\title{
BEPS UNA POLÍTICA PROTECCIONISTA EN FAVOR DEL ERARIO
}

\author{
A protectionist policy in favor of the treasury
}

Araceli SEGOVIA BLANCO*

\begin{abstract}
Sumario:
'I. Introducción II. Antecedentes III. El Proyecto BEPS IV. Informes V. Países en desarrollo VI. México como miembro de la OCDE VII. Efectos de BEPS en México VIII. Instrumento Multilateral BEPS IX. Conclusiones X. Bibliografía
\end{abstract}

Resumen: La armonización entre los sistemas tributarios de todas las naciones ha sido un reto en los últimos tiempos, sobre todo a raíz de la detección de planeaciones fiscales que han causado menoscabo a muchos de ellos. Buscar alguna alternativa que eficiente la localización de este tipo de actividades fue una tarea en la que se involucró un buen número de elementos, sociedades, asociaciones, corporaciones, países, etc., esta labor fue encabezada por el G20 y dirigida por la OCDE, obteniendo como resultado un proyecto al que se le ha denominado BEPS, que consta de 15 acciones a implementar por aquellos países cuyas negociaciones no distinguen fronteras y que evidentemente en este mundo globalizado afecta a todos en general. Por su parte, México ha participado activamente desde sus inicios del proyecto, y así mismo ha ido incorporando estos estándares en su legislación, más adelante identificaremos algunas de las 15 acciones que han repercutido de inmediato y que han dado por origen nuevas obligaciones a los contribuyentes que se ubiquen en dicho supuesto.

Palabras Clave: Erosión de la Base Imponible, Acciones BEPS, traslado de beneficios, doble no tributación, proteccionista.

Abstract: The harmonization between the tax systems of all nations has been a challenge in recent times, especially following the detection of tax planning that has caused harm to many of them, to find an alternative that efficiently locates this type of activities, it was a task in which a good number of elements, societies, associations, corporations, countries, etc. were involved, this work was led by the G20 and by the OECD, obtaining as a result a project that is called BEPS, which consists of 15 actions to be implemented by those countries whose negotiations do not distinguish borders, and which evidently in this globalized world affects everyone in general. For its part, Mexico has actively participated since its inception of the project, and has also been incorporating these standards in its legislation, later, we will identify some of the 15 actions that have been passed immediately and that have given rise to new obligations to the taxpayers.

Keywords: Base Erosion, BEPS Actions, Profit Shifting, double no taxacion. Protectionist.

\footnotetext{
Estudiante de la Maestría en Fiscal por la Universidad de Guanajuato.
} 


\section{Introducción}

El estudio sobre precios de transferencia tiene como propósito informar sobre aquellas operaciones transnacionales que han llevado a cabo las empresas multinacionales que operan en México, siendo ello el precio que pactan dos empresas asociadas para transferir, entre ellas, bienes, servicios o derechos. Este precio es relevante en el ámbito tributario, cuando las entidades que pactan el precio tienen vínculos de propiedad o administración entre sí (entidades relacionadas), lo que podría facilitar que la fijación del precio no se realice en las mismas condiciones que hubiesen sido utilizadas por entidades que no mantengan estos vínculos (terceros o independientes). En dicho caso si la fijación del precio difiere del que se hubiese formado en un mercado abierto, competitivo y sin restricciones, implica que el precio permitiría distribuir beneficios entre empresas relacionadas de una manera que podría ser artificialmente favorable a alguna de las entidades.

Dicha obligación surge desde 2014, es por ello que en materia de regulación fiscal se han ido involucrando los responsables de la emisión de la información, los asesores y todas aquellas personas interesadas en conocer sobre dicho informe, en especial, en todo lo que refiere a la formalidad y el fondo de su cumplimiento, pues es menester saber que su presentación obedece no sólo a la obligación tributaria nacional, sino que también se da cumplimiento en el ámbito internacional de acuerdo con las regulaciones establecidas por la Organización para la Cooperación y el Desarrollo Económico (OCDE).

México ha adoptado la modalidad desde sus inicios en que la OCDE comenzó a emitir este tipo de regulaciones para sancionar actuaciones poco transparentes o aquellas que incluso siéndolo, denotaban perjuicio sobre algunos Estados en favor de sus estrategias corporativas. De esta forma, se ha visto en innumerables ocasiones que nuestro país se ubica dentro de la punta de lanza de aquellos que van adecuando sus regulaciones o legislación interna en razón de la exigibilidad, y en ocasiones, hasta en iniciativas del proceder internacional; a veces pareciera que por beneficio, otras por aceptación en su integración al grupo de las grandes economías, y en otras más, para demostrar su voluntad en el acatamiento de una nueva política internacional. Es entonces como se difunde internamente su incorporación desde la forma y sus reglas, sin embargo, poco se profundiza sobre su origen. Si bien es cierto, se suele referenciar que emana de una regulación de la OCDE, pero limitado exactamente a eso, a puntualizar que su fuente se encuentra en ese organismo, no se profundiza sobre las razones que propiciaron esta exigencia por parte de la OCDE y el grupo de los $20\left(\mathrm{G}_{2} \mathrm{O}\right)^{1}$ para su creación. Por ello en el presente trabajo se hablará de las regulaciones internacionales que se suscitaron alrededor este tema y su perfeccionamiento, según se presentaban incidencias así como la proyección de su implementación señalando los resultados que realmente se esperan.

\section{Antecedentes}

En 2012 sale a la luz pública un fraude millonario originado por empresas multinacionales cuyo origen se encuentra en Luxemburgo ${ }^{2}$, ya que es uno de los lugares de preferencia de capitales

\footnotetext{
${ }^{1}$ G20 Cumbre de San Petersburgo de 2013, se aprueba un Plan de Acción que garantice la fiscalidad internacional.

${ }^{2}$ [En línea] disponible en: https://uvadoc.uva.es/bitstream/10324/5903/1/TFG-O\%20169.pdf
} 
especulativos por sus ya conocidas políticas tributarias, su baja imposición, algunos fraudes corporativos y la captación de capital extranjero que buscan una baja tributación.

Este tipo de zonas que también son conocidas en el argot popular como paraísos fiscales forman parte inminente de la planeación estratégica fiscal potencialmente vendida entre los grupos empresariales que operan de manera internacional y que, por la factibilidad de traslado de capital, pueden de manera legal eludir los impuestos de algunas regiones. Como era de esperarse, este tipo de prácticas ha generado inconformidad por parte de aquellos Estados afectados en razón de que la percepción tributaria es baja e incluso nula, pues algunas de las prácticas comunes comienzan desde que se depositan en estos países de baja tributación los capitales generados en zonas de alta tributación o promedio.

Ante estas situaciones e incidentes que han ido en aumento no sólo en los territorios preferentes fiscalmente sino incluso en aquellos países que aun teniendo un costo tributario promedio podían gozar en algunos rubros de alguna excepción tributaria, el G2o instó a la OCDE para que regule y sancione estas prácticas; es así como nace el proyecto BEPS (del inglés Base Erosion and Profit Shifting), que en español significa Erosión de la Base Imponible y el Traslado de Beneficios (EBITB), cuyo término designa en fiscalidad internacional las estrategias de planificación fiscal utilizadas por las empresas multinacionales para aprovecharse de las discrepancias, lagunas, mecanismos no deseados e inconsistencias de los sistemas fiscales nacionales y trasladar sus beneficios a países de escasa o nula tributación, donde las entidades ejercen o tienen poca actividad económica y eludir de esta forma el pago de impuestos ${ }^{3}$.

\section{El proyecto BEPS}

Así se conoce la iniciativa puesta en marcha por la Organización para la Cooperación y el Desarrollo Económico, que trata de combatir las prácticas de elusión fiscal a nivel internacional. A partir de septiembre del año $2013^{4}$, nace como un Proyecto del G2O, el cual emana como una consecuencia de la observación de acciones que no sólo contemplaba estrategia fiscal para bajar la tributación, sino para nulificarla, de ello surge precisamente la necesidad de regular el comportamiento de las economías con presencia internacional, o por lo menos, las que integran al grupo perteneciente a las mencionadas agrupaciones internacionales. Es importante resaltar que en el compromiso adquirido se observa un estándar en la entrega de información, igualmente se había observado por parte de grupos empresariales que al llevar a cabo este tipo de acciones les provoca un ahorro significativo, incurriendo incluso en la doble no tributación.

Aquí cabe destacar que tradicionalmente los organismos económicos internacionales como la OCDE se habían ocupado de corregir los problemas de doble imposición internacional derivado de la internacionalización de la economía, pero la crisis fiscal derivada de la crisis económica iniciada en 2008 y la creciente erosión de las bases imponibles correspondientes a los beneficios empresariales han llevado a trasladar la cuestión y a evitar la doble no imposición internacional o la reducción intencionada e ilegal de la imposición sobre las rentas o patrimonios internacionales, mediante el aprovechamiento del tratamiento fiscal dispar entre las distintas

\footnotetext{
3 OCDE. El proyecto BEPS y los países en desarrollo: de las consultas a la participación, [en línea] disponible en: http://www.oecd.org/ctp/estrategia-fortalecimiento-paises-en-desarrollo.pdf

4 Action Plan on Base Erosion and Profit Shifting (COCDE 2013
} 
jurisdicciones fiscales y la utilización de esquemas de planificación fiscal, que en muchos casos puede ser calificada como agresiva o abusiva 5 .

La OCDE por mucho tiempo se ha preocupado por regular y evitar la doble tributación, por disminuirla, y mejor aún, desaparecerla, en razón de que se sabe bien que estas prácticas o errores tributarios desalientan la inversión de aquellas multinacionales que han promovido la economía globalizada, fomentado el crecimiento en razón de empleo, aumento del Producto Interno Bruto (PIB), etcétera. Sin embargo, las regulaciones tributarias internacionales no están operando de manera similar, y esto obedece por supuesto a la soberanía que cada Estado conserva y al que sin cuestionamiento alguno se tiene derecho; no obstante, esta no consolidación de regulaciones impositivas ha sido abusada y proyectada a planeaciones agresivas, que están causando un menoscabo significativo en la recaudación de algunos Estados.

El término BEPS hace referencia a las estrategias de planificación fiscal recurridas por aquellas empresas, que aprovechando la frágil coordinación entre los sistemas tributarios de los países involucrados, en las operaciones financieras de sus multinacionales, logran traspasar sus utilidades a causa de la gran movilidad de sus capitales, y éstos son colocados en aquellas zonas cuyo beneficio se potencializa a causa de la baja imposición, provocando un perjuicio en las finanzas al lugar de origen del ingreso, lo cual les ha permitido eludir el impuesto.

Dicho de otra manera, BEPS hace referencia a la erosión de la base imponible y al traslado de beneficios propiciados por la existencia de lagunas o mecanismos no deseados entre los distintos sistemas impositivos nacionales, de los que pueden servirse las empresas multinacionales (EMN) con el fin de hacer "desaparecer" beneficios a efectos fiscales, o bien, de trasladar beneficios hacia ubicaciones donde existe escasa o nula actividad real, si bien goza de una débil imposición, derivando en escasa o nula renta sobre sociedades. Al tenor de la creciente movilidad del capital y de activos tales como la propiedad intelectual, así como de los nuevos modelos de negocio del siglo XXI, BEPS se ha convertido en un serio problema ${ }^{6}$.

También al preguntarse sobre BEPS, la OCDE mencionó que constituye un factor crítico en la actualidad dado que la crisis económica mundial ha restringido las finanzas públicas, obligando a los gobiernos a efectuar recortes en sus gastos y servicios, o bien, a elevar sus impuestos para aumentar sus ingresos. Ante este panorama económico, los problemas de BEPS han supuesto un importante menoscabo al buen funcionamiento del sistema impositivo. Tanto los contribuyentes a título individual como las empresas nacionales soportan una mayor carga impositiva que las empresas internacionales que consiguen tributar a un tipo impositivo bajo o nulo. Las propias empresas multinacionales $(\mathrm{EMN})$ han de hacer frente a un riesgo importante para su reputación, dado el interés que suscita el ámbito fiscal empresarial cada vez que las empresas operan en mercados internos tienen dificultades a la hora de competir con las multinacionales que cuentan con recursos para trasladar sus beneficios más allá de sus fronteras para eludir o reducir sus impuestos. De esta forma los gobiernos perciben ingresos inferiores ${ }^{7}$.

\footnotetext{
5 Carbajo Vasco, Domingo (2015), "El plan de acción de la iniciativa BEPS. Una perspectiva empresarial”, Crónica Tributaria Núm. 154/2015 (49-67), [en línea] disponible en: http://www.ief.es/documentos/recursos/publicaciones/revistas/cron_trib/154_carbajo.pdf

6 OCDE, 10 preguntas sobre BEPS, [en línea] disponible en: www.oecd.org/tax/beps.htm

7 OCDE, 10 preguntas sobre BEPS, [en línea] disponible en: www.oecd.org/tax/beps.htm 


\section{Informes}

Como se mencionó previamente, la primera iniciativa BEPS de 2013 pretendía regular las operaciones financieras entre partes relacionadas, de donde nace la necesidad de transparentar las operaciones y eliminar la doble tributación, por esta razón, se crean como medida de control tres documentos a entregar a las dependencias tributarias en cada Estado: el Archivo Maestro, el Archivo Local y el Informe País por País, que forman parte de esta primera iniciativa, la cual, en su momento, fue buen punto de partida pero no suficiente, resultando de ello una pérdida recaudatoria en el impuesto sobre sociedades ${ }^{8}$; en México se le denomina Impuesto Sobre la Renta (ISR) de un 4 a 10\% de la recaudación global, lo que se traduce en un monto aproximado de 100 a 240 millones de dólares anuales 9 .

Como era de esperarse, BEPS tenía que mostrar una evolución a partir de su creación, y en efecto, este proyecto se ha ido modificando en razón de la supletoriedad de parte de los que se han involucrado en su proceso y, sobre todo, de quienes ya lo comenzaban a incorporar. Sin duda era la única forma de verificar si el documento cumplía con su objetivo o bien requería algunos complementos para su mejora, y es así como se da una primera revolución. En las modificaciones al proyecto en 2015 se comienza a regular con más precisión pues en tanto no se reglamentaran las normas hasta el momento vigentes, las acciones perniciosas seguirían operando sin ninguna amonestación; entonces, se puntualiza que, entre otros intereses, BEPS buscaría que los beneficios quedaran gravados en el lugar de donde emana el valor de las actividades económicas que se desarrollan y que les da origen.

Esta iniciativa tuvo tan buena aceptación que la OCDE, el G2o y un número importante de países en desarrollo han trabajado coordinadamente para lograr un resultado exitoso de este proyecto. Ha sido tal el impacto que se ha logrado involucrar a organizaciones fiscales regionales como el Foro Africano de Administración Tributaria (ATAF), Centro de Encuentros y Estudios de Dirigentes de Administraciones Fiscales (CREDAF), Centro Interamericano de Administraciones Tributarias (CIAT), Fondo Monetario Internacional (FMI), Organización de las Naciones Unidas (ONU), y por supuesto la sociedad civil, la cual ha colaborado haciendo un aporte importante en foros especializados, webcast, redes sociales y por cualquier otro medio de difusión masiva que ha tenido a su alcance.

Una vez que se identificaron las acciones recurridas en las planeaciones agresivas, se comenzaron a reforzar las políticas tributarias, se crearon nuevos mecanismos de integración de la información basado en 15 documentos y se proporcionaron medidas de apoyo para ayudar a los países en desarrollo, de los que se hablará más adelante, pero es mayormente importante precisar que estos territorios resultan ser los más afectados en razón de que la fuente principal de su economía emana del impuesto sobre sociedades o las ganancias (Renta).

Son muchos los problemas que se deben erradicar, no sólo la fuga de capitales, aunque ésta representa un cuantioso decremento, sino también prácticas como normas fiscales internas, la opacidad tributaria, la baja recaudación en razón de su política interna, los costos excesivos de

\footnotetext{
8 Tributo de manera directa, que grava la renta de las sociedades.

9 Proyecto BEPS - nota explicativa
} 
revisión, la nula coordinación entre los países, etcétera, permiten al elusor ${ }^{10}$ hacer uso de estas prácticas, a sabiendas de que las consecuencias serán prácticamente nulas.

Aunque evitarlo puede ser posible, únicamente se requiere de la cooperación de los países involucrados y trabajar coordinadamente en pro de una equidad entre los sistemas tributarios que garanticen que la legislación internacional les favorece y les protege de acuerdo a su observancia.

Inclusive, adaptarse tributariamente al comercio globalizado en razón de la innovación presentada, representa día con día un gran reto nacional e internacional. La promoción de esas 15 acciones son resultado de las prácticas que pueden llevar incluso años en el mercado sin regulación, pero dejarlas al descubierto provocan un estado de indefensión sobre actividades regulares y una muy posible recesión de su economía; de ahí que llevar a la vanguardia las obligaciones fiscales hará que el comercio internacional sea más equitativo en su accionar.

El informe país por país contiene información sobre los ingresos, impuestos, beneficios, cantidad de trabajadores, capital, utilidades no distribuidas y activos, así como el señalamiento de las jurisdicciones tributarias que lo integran. Este documento es importante en razón de que muestra una amplia radiografía sobre la composición de las multinacionales, su influencia en otras entidades y el riesgo al que se expone el país, en razón de aquellos países con los que las multinacionales tienen intereses.

Las 15 acciones que incluye el BEPS quedarán reflejadas en informes que tendrán las autoridades tributarias de cada país, a las cuales se tendrá acceso y servirá para mediar vigilancia en su cumplimiento y erradicar acciones perniciosas. Los archivos descritos previamente están enlistados como reglas internacionales dictadas por la OCDE, sin embargo, es imperante señalar que la legislación local debe acoger a dicho ordenamiento como medida regulatoria a fin de prevenir una posible contraveniencia al mandato nacional. La OCDE se ha dado a la tarea de diseñar guías cuyo propósito es indicar y enumerar la documentación requerida para el cumplimiento del proyecto, así como la justificación del proceso en caso de necesitar aportar pruebas de su cabal cumplimiento.

No obstante, la gran mayoría de las estructuras utilizadas por los contribuyentes son legales, y por tanto, no incumplen con el sistema tributario, ni con las normas de cada país. Por ello han razonado que tales empresas cumplen con el sistema, pero aun así el aporte fiscal es bajo, lo que corresponde es un cambio de reglas. BEPS representa un Plan de Acción con 15 medidas concretas que distintos países, principalmente de OCDE, buscan adoptar en sus legislaciones internas y convenios internacionales, a fin de cerrar portillos y aumentar la recaudación de las grandes empresas multinacionales ${ }^{11}$.

En ese contexto, la OCDE emitió los documentos finales del proyecto Plan de Acción contra la Erosión de la Base y Traslado de Beneficios, mejor conocido como BEPS por sus siglas en inglés, lanzado en julio de 2013, y que establece los siguientes objetivos, entre otros:

1. Atender retos fiscales de la economía digital;

\section{Neutralizar inconsistencias en acuerdos híbridos;}

\footnotetext{
${ }^{10}$ Es la persona que hace una acción o efecto de eludir su responsabilidad fiscal, pero de una manera estratégica, astuta y manteniendo entre la legalidad y lo éticamente reprochable.

${ }^{11}$ GonzÁlez, Rafael (2014), ¿Qué es el BEPS? Puede ser el inicio de una nueva era en fiscalidad internacional, [en línea] disponible en: http://elfinancierocr.com/economia-y-politica/que-es-el-beps-puede-ser-el-inicio-de-unanueva-era-en-fiscalidad-internacional/
} 
3. Fortalecer reglas de las empresas extranjeras controladas;

4. Limitar erosión a través de deducción de intereses y otros pagos financieros;

5. Atacar prácticas fiscales nocivas;

6. Prevenir abuso de tratados;

\section{Prevenir evasión artificial de la caracterización de establecimiento permanente;}

8-10. Asegurar que los precios de transferencia están en línea con la creación de valor: Activos intangibles, riesgos y capital y otras transacciones de alto riesgo;

11. Establecer metodologías para recabar y analizar información relevante para BEPS;

12. Requerir la revelación de arreglos de planeación fiscal agresiva;

13. Re-evaluar la documentación de precios de trasferencia;

14. Mejorar efectividad de mecanismos para resolución de disputas; $y$,

15. Desarrollar un instrumento multilateral para acciones anti-BEPS.

Por esta razón, como lo señala Rafael González, BEPS es visto como el "nuevo paradigma" de la fiscalidad internacional, ya que podría representar un cambio total en la forma en que los Estados afrontan las rentas obtenidas por empresas y grupos con operaciones en dos o más jurisdicciones.

\section{Los paises en desarrollo}

Dadas las circunstancias económicas y el pausado crecimiento que caracteriza a los países en desarrollo, es mandatorio que la OCDE incluya dentro de su proyecto a estas economías de una manera proteccionista. Finalmente, estos países recaen en el rango más crítico del riesgo que representan las prácticas BEPS, y es imperante destinar apoyo que les permita enfrentar las vicisitudes por las prácticas agresivas de las multinacionales. Este tipo de economía tiene como características no tener una baja imposición, en cambio, suele tener políticas que favorecen a la captación de capitales extranjeros, lo cual resulta altamente atractivo con relación al costo que les genera, especialmente, en la mano de obra. Sin embargo, el beneficio no es reciproco, porque la estrategia prevista les permite hacer operaciones planeadas de tal manera que pueda desviar su ingreso a una localidad menos gravosa.

Esto afecta considerablemente a los países en desarrollo, en virtud de que su principal fuente de financiamiento proviene de los impuestos sobre sociedades (Renta), y si este no es percibido de una manera equitativa, la crisis económica de estas zonas continuará. Al involucrar a estas economías emergentes se amplió el proyecto, pues se pudo actuar en razón a las prioridades expuestas.

De esta manera se diseña un informe adicional simplificado, donde además de la atención puesta en la limitación de la erosión de la base tributaria a través de la deducción de intereses y otras cargas financieras ${ }^{12}$, se toman en cuenta las acciones de: prevención del abuso de los tratados fiscales y las medidas para evitar la elusión artificiosa del estatuto de establecimiento

\footnotetext{
${ }^{12}$ Acción 4 Plan de Acción BEPS
}

CIENCIA JURÍDICA. Departamento de Derecho. División de Derecho, Política y Gobierno, Universidad de Guanajuato - Año 7, No. 14, 2018 
permanente $^{13}$, los precios de transferencia, en particular, los pagos que erosionan la base imponible ${ }^{14}$ y la documentación sobre precios de transferencia y de informes país por país ${ }^{15}$.

\section{México como miembro de la OCDE}

México ha formado parte de la OCDE desde $1994^{16}$, su ingreso causó sorpresa para los miembros y los no miembros de esta organización debido a que habían pasado veinte años desde la última incorporación de algún país, pero fue más inesperada su aceptación porque llegaba a romper paradigmas, ya que era el primer país en desarrollo que conseguía su adhesión. Pareciera entonces que estaba alcanzando niveles económicos impactantes para el exterior, sin embargo, no era en realidad la posición económica lo que lo ubicaba en este contexto, sino que la OCDE asociaba a aquellas naciones cuyo denominador común de las economías que la integran fuese compartir valores y experiencias que le permitieran identificar problemas comunes y encontrar soluciones conjuntas.

Al formar México parte de la OCDE no sólo consiguió prestigio a nivel internacional, sino que también se obligó a dar cumplimiento sobre aquellas políticas instauradas por la misma organización, y a participar activamente en la mejora de un entorno social, político, económico y cultural del momento que se viva. México forma parte de la OCDE:

OCDE es tal vez la entidad internacional cuyos, funcionamiento y estructura se apegan en mayor medida al principio de igualdad soberana. Las políticas que se proponen en su seno se aplican en los tiempos y las modalidades propios de cada país con base en sus legislaciones nacionales. Todas las decisiones se toman por consenso, por lo que no se discuten en el Consejo hasta que los países miembros -mediante los comités- las han estudiado, analizado y ponderado cuidadosamente [....] México cumple con el principio de no discriminación, excepto en lo que atañe al establecimiento de bancos, casas de bolsa y compañías de seguros, ya que se otorga un trato preferencial a las inversiones provenientes de los países firmantes del TLC. México se comprometió- a revisar ese tratamiento y considerar la extensión de los beneficios del Tratado -en servicios financieros- a todos los miembros de la OCDE a más tardar a principios de $1998 .{ }^{17}$

Como parte de estos compromisos y en relación a la gestión de cumplimiento, este organismo realiza análisis anuales sobre los resultados macroeconómicos con los que está operando cada asociado, en los que enfatiza las recomendaciones de mejora, observa puntualmente las desviaciones encontradas, destaca aquellos focos rojos donde se considera que el país analizado debe tener precaución antes de que ponga en riesgo su afiliación y reconoce las acciones emprendidas en pro de su armonización a las políticas internacionales implementadas por el organismo.

\footnotetext{
$\overline{13}$ Acciones 6 y 7 Plan de Acción BEPS

14 Acciones 8, 9 y 10 Plan de Acción BEPS

${ }^{15}$ Acción 13 Plan de Acción BEPS

${ }^{16}$ El ingreso de México a la OCDE - Victor Daniel Flores

${ }^{17}$ Andrés Rozenthal, Presentación del Subsecretario de Relaciones Exteriores, embajador Andrés Rozenthal, ante las Comisiones Unidas del Senado de la República, México, 6 de mayo de 1994.
} 


\section{Efectos de BEPS en México}

En los Estudios Económicos de la OCDE México, 2017 ${ }^{18}$, en el apartado destinado al aspecto fiscal, se hace referencia a las reformas fiscales, la recaudación de impuestos y la eficacia de los mismos, y reconoce, pese a que México muestra estadísticas elevadas de evasión, su cumplimiento en la incorporación de BEPS en su legislación desde 2014. Pero si bien este proyecto ya está adecuado en sus tributos aún le hace falta fortalecer las acciones BEPS en su totalidad, aunado con una eficiencia superior de fiscalización a fin de evitar la evasión antes mencionada. En sugerencia señala que armonizar las administraciones en materia tributaria en los aspectos seguridad social, impuestos federales, estatales y locales, tendría como resultado una optimización de recursos de fiscalización y una captación superior, ya que un mismo organismo abarcaría la revisión integral del aspecto fiscal del contribuyente, evitando resultados diferentes en cada uno de los rubros según la dependencia que revisa.

México por su parte y convencido del proyecto adecuó su reforma fiscal desde 2014, pero en 2016 incorporó la acción 13 como parte de las obligaciones de informar para aquellas empresas que se ubiquen en el supuesto de llevar operaciones entre partes relacionadas. Dichas acciones se ven reflejadas en el artículo 76-A de la Ley del Impuesto sobre la Renta (LISR) promulgada el 18 de Noviembre de 2015 en el Diario Oficial de la Federación (DOF). Con esta reforma insta al cumplimiento de la acción 13 del Proyecto que consiste en la elaboración del Archivo Maestro, Archivo Local e Informe de País por País. En caso de incumplimiento se prevé su sanción en el artículo 81 fracción XVII del Código Fiscal de la Federación (CFF), quien no sólo sanciona la omisión sino el error o la falta de información; asimismo, establece los criterios de deducción y los tipifica en el artículo 28 fracciones XXIX y XXXI de la Ley del Impuesto Sobre la Renta.

De esta misma manera, el Artículo 178 de la Ley del Impuesto Sobre la Renta intenta adecuar el procedimiento del análisis de precios de transferencia de acuerdo con lo estipulado en las acciones 8 - 10: Asegurar que los precios de transferencia están en línea con la creación del valor. Que a la letra dice:

Acciones 8-10 - Asegurar que los resultados de los precios de transferencia están en línea con la creación de valor. ${ }^{19}$

Las normas de precios de transferencia, establecidas en el artículo 9 de los convenios fiscales basados en los Modelos de Convenio de la OCDE y de la ONU y en las Directrices de Precios de Transferencia, se emplean para determinar, de acuerdo al principio de plena competencia, las condiciones, incluyendo el precio, de las transacciones dentro de un grupo multinacional. Se han reforzado y clarificado los estándares actuales en este ámbito, incluyendo unas pautas sobre el principio de plena competencia y el establecimiento de una metodología para garantizar la determinación de precios adecuados para los intangibles de difícil valoración de acuerdo al principio de plena competencia. El trabajo se ha centrado en tres áreas clave. La Acción 8 examinó las cuestiones relativas a precios de transferencia de operaciones vinculadas que involucraban activos intangibles, dado que este tipo de activos son por definición móviles y con frecuencia difíciles de valorar. La distribución inadecuada de los beneficios generados por intangibles valiosos ha contribuido en gran medida a la erosión de la base imponible y al traslado de beneficios. Por su parte, la Acción 9 se ocupa de la atribución contractual de riesgos, concluyendo que sólo se respetarían cuando dichas atribuciones se correspondieran efectivamente

\footnotetext{
${ }^{18}$ Estudios Económicos de la OCDE Mexico 2017 - OCDE

${ }^{19}$ NOTA EXPLICATIVA $\odot$ OCDE 2015
} 
con la toma de decisiones $y$, por ende, con el ejercicio de un control efectivo sobre tales riesgos. La Acción 10 se ha concentrado en otras áreas de alto riesgo, como la atribución de beneficios resultante operaciones vinculadas que carecen de lógica comercial, el uso selectivo de métodos de precios de transferencia con el objeto de desviar los beneficios derivados de las actividades económicamente más importantes del grupo multinacional, y el uso de ciertos tipos de pagos entre miembros del grupo multinacional (como gastos de gestión o gastos correspondientes a la sede principal) para erosionar la base imponible sin que exista una correspondencia con la creación de valor. El informe combinado contiene directrices revisadas que dan respuesta a estas cuestiones, garantizando así que las normas de precios de transferencia ofrezcan resultados que alineen mejor los beneficios operativos y las actividades económicas que los generan.

El informe contiene igualmente directrices sobre transacciones transfronterizas que involucran materias primas o servicios intragrupo de bajo valor añadido. Como estas dos cuestiones fueron identificadas como de importancia decisiva de para los países en vías de desarrollo, las directrices se verán complementadas con un trabajo adicional, a iniciativa del Grupo de Trabajo sobre Desarrollo del G20, que proporcionará conocimiento, mejores prácticas y herramientas a los países en vías de desarrollo para valorar las transacciones de materias primas a efectos de la aplicación de las normas de precios de transferencia y para prevenir la erosión de sus bases imponibles a través de pagos que erosionan la base.

Por su parte, nuestra legislación señala ${ }^{20}$ :

Artículo 178. Los contribuyentes de este Título, además de las obligaciones establecidas en otros artículos de esta Ley, deberán presentar en el mes de febrero de cada año, ante las oficinas autorizadas, declaración informativa sobre los ingresos que hayan generado o generen en el ejercicio inmediato anterior sujetos a regímenes fiscales preferentes, o en sociedades o entidades cuyos ingresos estén sujetos a dichos regímenes, que corresponda al ejercicio inmediato anterior, acompañando los estados de cuenta por depósitos, inversiones, ahorros o cualquier otro, o en su caso, la documentación que mediante reglas de carácter general establezca el Servicio de Administración Tributaria. Para los efectos de este artículo, se consideran ingresos sujetos a regímenes fiscales preferentes, tanto los depósitos como los retiros. La declaración a que se refiere este artículo, será utilizada únicamente para efectos fiscales.

No obstante lo dispuesto por este Capítulo, los contribuyentes que generen ingresos de cualquier clase provenientes de alguno de los territorios señalados en las disposiciones transitorias de esta Ley, así como los que realicen operaciones a través de figuras o entidades jurídicas extranjeras transparentes fiscalmente a que se refiere el artículo 176 de la misma, deberán presentar la declaración informativa prevista en el párrafo anterior, sin que por este solo hecho se considere que se están generando ingresos sujetos a regímenes fiscales preferentes, salvo que se ubiquen en alguno de los supuestos previstos en el artículo 176 de esta Ley, o cuando no cumplan con la presentación de la declaración informativa a que se refiere este párrafo.

El titular y los cotitulares de los ingresos previstos en el primer párrafo de este artículo serán quienes deberán presentar la declaración antes señalada y las instituciones financieras sólo estarán relevadas de presentar la misma, siempre que conserven copia de la declaración presentada en tiempo y forma por el titular y cotitulares de los ingresos sujetos a un régimen fiscal preferente.

\footnotetext{
${ }^{20}$ Ley del Impuesto Sobre la Renta

CiEnCIA JuRídica. Departamento de Derecho. División de Derecho, Política y Gobierno, Universidad de Guanajuato - Año 7, No. 14, 2018
} 
Se considera que el contribuyente omitió la presentación de la declaración a que hace referencia este artículo, cuando no contenga la información relativa a la totalidad de los ingresos que el contribuyente haya generado o genere sujetos a regímenes fiscales preferentes que correspondan al ejercicio inmediato anterior.

Artículo 179. Los contribuyentes del Título II de esta Ley, que celebren operaciones con partes relacionadas residentes en el extranjero están obligados, para efectos de esta Ley, a determinar sus ingresos acumulables y deducciones autorizadas, considerando para esas operaciones los precios y montos de contraprestaciones que hubieran utilizado con o entre partes independientes en operaciones comparables.

En el caso contrario, las autoridades fiscales podrán determinar los ingresos acumulables y deducciones autorizadas de los contribuyentes, mediante la determinación del precio o monto de la contraprestación en operaciones celebradas entre partes relacionadas, considerando para esas operaciones los precios y montos de contraprestaciones que hubieran utilizado partes independientes en operaciones comparables, ya sea que éstas sean con personas morales, residentes en el país o en el extranjero, personas físicas y establecimientos permanentes en el país de residentes en el extranjero, así como en el caso de las actividades realizadas a través de fideicomisos.

Para los efectos de esta Ley, se entiende que las operaciones o las empresas son comparables, cuando no existan diferencias entre éstas que afecten significativamente el precio o monto de la contraprestación o el margen de utilidad a que hacen referencia los métodos establecidos en el artículo 180 de esta Ley, y cuando existan dichas diferencias, éstas se eliminen mediante ajustes razonables. Para determinar dichas diferencias, se tomarán en cuenta los elementos pertinentes que se requieran, según el método utilizado, considerando, entre otros, los siguientes elementos:

I. Las características de las operaciones, incluyendo:

a) En el caso de operaciones de financiamiento, elementos tales como el monto del principal, plazo, garantías, solvencia del deudor y tasa de interés.

b) En el caso de prestación de servicios, elementos tales como la naturaleza del servicio, y si el servicio involucra o no una experiencia o conocimiento técnico.

c) En el caso de uso, goce o enajenación, de bienes tangibles, elementos tales como las características físicas, calidad y disponibilidad del bien.

d) En el caso de que se conceda la explotación o se transmita un bien intangible, elementos tales como si se trata de una patente, marca, nombre comercial o transferencia de tecnología, la duración y el grado de protección.

e) En el caso de enajenación de acciones, se considerarán elementos tales como el capital contable actualizado de la emisora, el valor presente de las utilidades o flujos de efectivo proyectados o la cotización bursátil del último hecho del día de la enajenación de la emisora.

II. Las funciones o actividades, incluyendo los activos utilizados y riesgos asumidos en las operaciones, de cada una de las partes involucradas en la operación.

III. Los términos contractuales.

IV. Las circunstancias económicas. 
$V$. Las estrategias de negocios, incluyendo las relacionadas con la penetración, permanencia y ampliación del mercado.

Cuando los ciclos de negocios o aceptación comercial de un producto del contribuyente cubran más de un ejercicio, se podrán considerar operaciones comparables correspondientes de dos o más ejercicios, anteriores o posteriores.

Se considera que dos o más personas son partes relacionadas, cuando una participa de manera directa o indirecta en la administración, control o capital de la otra, o cuando una persona o grupo de personas participe directa o indirectamente en la administración, control o capital de dichas personas. Tratándose de asociaciones en participación, se consideran como partes relacionadas sus integrantes, así como las personas que conforme a este párrafo se consideren partes relacionadas de dicho integrante.

Se consideran partes relacionadas de un establecimiento permanente, la casa matriz u otros establecimientos permanentes de la misma, así como las personas señaladas en el párrafo anterior y sus establecimientos permanentes.

Salvo prueba en contrario, se presume que las operaciones entre residentes en México y sociedades o entidades sujetas a regímenes fiscales preferentes, son entre partes relacionadas en las que los precios y montos de las contraprestaciones no se pactan conforme a los que hubieran utilizado partes independientes en operaciones comparables.

Para la interpretación de lo dispuesto en este Capitulo, serán aplicables las Guías sobre Precios de Transferencia para las Empresas Multinacionales y las Administraciones Fiscales, aprobadas por el Consejo de la Organización para la Cooperación y el Desarrollo Económico en 1995, o aquéllas que las sustituyan, en la medida en que las mismas sean congruentes con las disposiciones de esta Ley y de los tratados celebrados por México.

Como se puede apreciar, a pesar de estar adecuada la legislación a las necesidades de BEPS, estos ordenamientos aún no están en plena concordancia, y pese a que el último párrafo exime a la legislación mexicana de hacer algún cambio, pues alude a las guías de BEPS para su cumplimiento, jurídicamente éstas no podrán ser exigidas en su totalidad si no se indican específicamente las acciones por las que debe actuar según el proyecto y, tratándose de formalidades que afectan la esfera jurídica del contribuyente, es imposible dejarlo a la interpretación. El proyecto debe ser específico, en espera de que durante el próximo año quede la adecuación.

La anticipación de México a su cumplimiento antes incluso de su solicitud, resultó un tanto incierta, sin embargo, se considera que es parte de la estrategia de nuestro país a fin de que cuando se tenga la solicitud formal de envío, se hayan cubierto muchas de las incógnitas que aún surgen sobre su presentación.

\section{Instrumento multilateral BEPS}

Como se mencionó, el avance del proyecto BEPS ha propiciado cambios internos y externos tanto del propio ordenamiento, como en cada uno de los países que se incorporan a este proyecto, y con base en ello se crea un grupo ad-hoc, el cual fue indicado en la acción o medida 15 y tiene como función desarrollar un Instrumento Multilateral que tiene como propósito la incorporación de todos los tratados internacionales, es decir, por el solo hecho de que los países 
firmen dicho Convenio se considera incorporado al proyecto BEPS sin necesidad de modificar los tratados internacionales con los que se tiene convenio o relación.

México, el pasado o7 de Junio de 2017, firmó la Convención Multilateral, por lo que el proyecto BEPS cobra mayor fuerza para nuestro país, sobre todo con aquellos países que también han incorporado dicho convenio, teniendo como caso excepcional las negociaciones con Estados Unidos que no son afectadas debido a que este país no firmó la convención, de modo que las reglas BEPS no le serán aplicables al tratado internacional firmado con el vecino país del norte.

\section{Conclusiones}

Como se pudo apreciar, la implementación del proyecto BEPS trae consigo un gran reto pues logró la movilidad de muchos países interesados en la regulación de acciones perniciosas, que aunque ya se tenían identificadas no se podían actuar en contra de ellas dada su legalidad o en razón de que estrictamente no violaban alguna formalidad, tratado internacional o la propia legislación interna, en tanto que no se había contemplado dicha incidencia. Entonces, ¿cómo no habrían de interesarse? si adoptar el proyecto promete equilibrar las acciones y salvaguardar la fuente que los origine, el deterioro causado y la recesión observada por este tipo de acciones, lo cual ira disminuyendo en la medida que se implementen las acciones propuestas.

No obstante, como el proyecto es tan ambicioso que implementarlo de manera inmediata resultaría casi imposible, aunque ya está por fenecer el periodo de gracia que otorgó la OCDE para su adecuación (2020), en tanto las normas internas de cada Estado trabajen en la misma dirección, por su puesto encaminados por la propia OCDE en cuanto a que se sigan emitiendo guías de acción para su ajuste en caso de encontrar posibles desviaciones.

México tendrá que resolver muchas anomalías que aún dejan incierto el camino de este proyecto, aunque, como se observó, ya dio un primer paso. Sin embargo, las reglas previstas sólo contemplan la forma y no el modo de la información, por lo que será indispensable que el órgano legislativo regule las acciones y las incorpore de manera adecuada a la legislación.

Todo lo cual repercute directamente en la fiscalidad interna de los países, cuyas medidas son parte de un tema global no exclusivo de México. El hecho de que nuestro país esté de manera proactiva implementando estos nuevos requerimientos permitirá a las autoridades fiscales mexicanas desarrollar una evaluación de riesgos para evitar la erosión de la base gravable a través del traslado de utilidades, lo que se traduce en un mayor fortalecimiento del sistema fiscal del país. Así se han escuchado algunas voces.

\section{Bibliografia hemerográfica}

CARbajo VAsco, Domingo (2015), El plan de acción de la iniciativa BEPS. Una perspectiva empresarial, Crónica Tributaria Núm. 154/2015 (49-67). [en línea] disponible en: http:// www.ief.es/documentos/recursos/publicaciones/revistas/con-trib/154_carbajo.pdf

Flores, Victor Daniel (1994), El Ingreso de México a la OCDE. Revista Comercio Exterior, Junio de 1994. [en línea] disponible en: http://revistas.bancomext.gob.mx/rce/magazines/36o/22/RCE16.pdf

GonzÁLez, Rafael (2014), ¿Qué es el BEPS? Puede ser el inicio de una nueva era en fiscalidad internacional. [en línea] disponible en: http://elfinancierocr.com/economia-y-politica/ que-es-el-beps-puede-ser-el-inicio-de-una-nueva-era-en-fiscalidad-internacional/ 
IMPC (2017), Nota explicativa del convenio multilateral para implementar medidas relativas a los tratados tributarios para prevenir la erosión de la base y el traslado de utilidades. [en línea] disponible en: http://imcp.org.mx/wp-content/uploads/2017/o4/ANEXO-NOTICIAS-FISCALES-117.pdf

OCDE (2011), Reforma Fiscal para una Economía más fuerte, más justa y más amplia. Estudios económicos de la OCDE: México.

OCDE (2013) Action Plan on Base Erosion and Profit Shifting

OCDE (2014), Proyecto BEPS y los países en desarrollo de las consultas de participación, [en línea] disponible en: http://www.oecd.org/ctp/estrategia-fortalecimiento-paises-en-desarrollo.pdf

OCDE (2015). Proyecto BEPS - Nota Explicativa. Proyecto de la OCDE y del G2o sobre la Erosión de la Base Imponible y el Traslado de Beneficios. Informes Finales.

OCDE (2016), Documentación sobre Precios de Transferencia e informe País por País.

OCDE (2017), Estudios Económicos de la OCDE: México, 2017.

OCDE. El proyecto BEPS y los países en desarrollo: de las consultas a la participación, [en línea] disponible en: http://www. Oecd.org/ctp/estrategia-fortalecimiento-paises-en-desarrollo.pdf

OCDE, 10 preguntas sobre BEPS, [en línea] disponible en: www.oecd.org/tax/beps.htm

REAL ACADEMIA ESPAÑOLA, Diccionario de la Lengua Espanola, Ed. Espasa-Calpe, 2012, $22^{\text {a }}$ ed. Madrid, España.

Tributo de Manera Directa, que grava la renta de las sociedades.

\section{Legislacion}

Constitución Política de los Estados Unidos Mexicanos

Ley de Impuesto Sobre la Renta

\section{Páginas web}

http://www.oecd.org/tax/la-ocde-presenta-los-resultados-del-proyecto-beps-de-la-ocde-yel-g2o-para-su-discusion-en-la-reunion-de-los-ministros-de-finanzas-del-g2o.htm

https://uvadoc.uva.es/bitstream/10324/5903/1/TFG-O\%20169.pdf

https://www.eleconomista.com.mx/sectorfinanciero/Prodecon-Convenio-Multilateral-deBEPS-listo-para-su-firma-20170126-0120.html 
http://www.ey.com/Publication/vwLUAssets/ey-tax-flash-instrumento-multilateral-beps-primera-parte/\$FILE/ey-tax-flash-instrumento-multilateral-beps-primera-parte.pdf

http://contaduriapublica.org.mx/que-es-beps/

http://www.keepeek.com/Digital-Asset-Management/oecd/taxation/plan-de-accioncontra-la-erosion-de-la-base-imponible-y-el-traslado-de-beneficios/plan-deaccion_9789264207813-4-es

http://www.oecd.org/ctp/beps-actions.htm

http://www. Oecd.org/ctp/estrategia-fortalecimiento-paises-en-desarrollo.pdf

http://www.ief.es/documentos/recursos/publicaciones/revistas/con_trib/154_carbajo.pdf

www.oecd.org/tax/beps.htm

http://elfinancierocr.com/economia-y-politica/que-es-el-beps-puede-ser-el-inicio-de-unanueva-era-en-fiscalidad-internacional/ 
